\title{
Coaliciones políticas y comportamiento electoral en la Ciudad de México: las elecciones del 2018*
}

\author{
Political Coalitions and Voter Behavior in Mexico City: \\ 2018 Elections
}

\author{
HÉCTOR TEJERA GAONA**
}

\begin{abstract}
The objective of this article is to analyze the political coalitions formed during the 2018 elections in Mexico and their effect on the proselytizing party modalities, as well as on citizens' perception of political parties and campaigns. For such an analysis an investigation based on ethnographic studies made from different municipalities in Mexico City was designed. It shows that coalitions did not have the electoral effect the coalition parties' leaders intended, due in part to candidates' apprehension of vote dispersal as well as citizen's reluctance to bear with coalitions integrated by parties they considered opposing or that they repudiated.
\end{abstract}

Key words: culture, parties, territories, alliances, citizenship, political conflicts

\begin{abstract}
Resumen
El objetivo del artículo es analizar las coaliciones políticas formadas en las elecciones de 2018 en México y su efecto en las modalidades de proselitismo partidario, así como en la percepción ciudadana sobre los partidos políticos y las campañas. Para dicho análisis se diseñó una investigación basada en estudios etnográficos realizados en diferentes delegaciones de la Ciudad de México. Se muestra que las coaliciones no tuvieron el efecto electoral que pretendieron los dirigentes de los partidos coaligados, debido tanto al temor de los candidatos a que el voto se dispersara, como a la resistencia de los ciudadanos a sufragar por coaliciones que integraban a partidos que consideraban opuestos o que desconocían. Palabras clave: cultura, partidos, territorios, alianzas, ciudadanía, conflictos políticos
\end{abstract}

La coalición es el arte de llevar el zapato derecho en el pie izquierdo sin que salgan callos.

Guy Mollet

$\mathrm{E}$ 1 artículo indaga si la organización de las coaliciones partidarias formadas para competir en la contienda electoral de 2018 modificó las actividades proselitistas de los partidos políticos que las integraron. En otros términos, cómo se realizaron las campañas políticas para salvar ante los ojos de los votantes las contradicciones de haber formado coaliciones entre partidos con propuestas programáticas opuestas, como fue el caso de Por México al Frente, integrada por el Partido Acción Nacional (PAN), el Partido de la Revolución Democrática (PRD)

\footnotetext{
* Artículo recibido el $22 / 10 / 18$ y aceptado el 18/12/18.

** Universidad Autónoma Metropolitana, Unidad Iztapalapa, Departamento de Antropología. Av. San Rafael Atlixco núm. 186, col. Vicentina, Iztapalapa, 09340, Ciudad de México <tejeravirtual@gmail.com>.
} 
y Movimiento Ciudadano (MC), y de Juntos Haremos Historia, constituida por Movimiento de Regeneración Nacional (Morena), el Partido del Trabajo (PT) y el Partido Encuentro Social (PES), que coaligaron partidos antagónicos. ${ }^{1}$ Se muestran las prácticas y temáticas proselitistas que entrelazaron contenidos significativos para los ciudadanos en el ámbito de las coaliciones, de manera particular en el caso de Por México al Frente, pues los dos primeros partidos que la constituían fueron asociados a proyectos opuestos por los habitantes de la Ciudad de México. Asimismo se presentan las diferencias de las prácticas empleadas por dicha coalición y Juntos Haremos Historia, ya que también en ésta hubo quienes se opusieron a la misma, porque la propuesta del pes es de corte cristiano-evangélico y contraria a un programa de gobierno sustentado, por ejemplo, en el apoyo a los derechos de la mujer a decidir sobre su propio cuerpo, y el matrimonio de personas del mismo sexo. Además, hasta ese momento, el PEs había sido aliado del PAN. ${ }^{2}$

Se tratan algunos elementos de cambio y continuidad vinculados a la formación de las coaliciones, buscando establecer qué tipo de procesos sociopolíticos asociados a las campañas electorales no se vieron afectados por esas oposiciones (es decir, si fueron hasta cierto punto similares a los encontrados en campañas electorales anteriores, o respondieron al contexto específico de la contienda electoral de 2018, sin estar relacionados más que de modo colateral con la integración de coaliciones).

Finalmente se exponen algunos efectos de las coaliciones sobre las percepciones de los habitantes de la Ciudad de México acerca de la política, los partidos y la democracia. Esto es, cómo fueron significadas entre los ciudadanos.

\section{¿Una "alianza contra natura"?: las coaliciones políticas}

El fenómeno político de las coaliciones forma parte de un proceso no exclusivo de México (Ruparelia, 2015; Lipset, 2017; Stefuriuc, 2015), inscrito en la disolución de las divergencias programáticas de los par- tidos como resultado de los procesos de cartelización, procesos mediante los cuales, de representantes de clases, sectores o grupos sociales, los partidos se han transformado en estructuras que buscan mantenerse en el poder "cachando de todo" (para lo cual una de sus estrategias es formar coaliciones) (Kitschelt, 2018), y garantizando (gracias a dicha cartelización) que el Estado los subvencione, pasando de ser entidades de interés público a formar parte del gobierno (Katz y Mair, 2009).

El pragmatismo como motor para la búsqueda del poder propicia tanto la desestructuración de los campos semánticos de la política tradicional y la generación de discursos fragmentados asociados a temas disgregados como la producción de nuevos performances monológicos durante las campañas electorales, donde actores descentrados cambian las ofertas programáticas por apelaciones a principios y valores como la lucha contra la corrupción, ${ }^{3}$ o formulan ofertas puntuales como la entrega de recursos a "las jefas" (madres de familia). ${ }^{4}$

Estos procesos de cartelización, al menos en el caso mexicano, son aglomeraciones de ofertas generales, difíciles de cumplir ante las limitaciones de la globalización y el control externo de las variables económicas, y con frecuencia contrarias a las políticas públicas efectivamente llevadas a cabo por los partidos. La cuestión ha sido debatida con amplitud, en especial para países que han tenido esta forma de organización partidaria y gubernamental desde hace muchos años. Con el fin de estudiarla, se han utilizado varias dimensiones de análisis: histórica, institucional, de relaciones horizontales y verticales, en espacios subnacionales y nacionales, dinámica interna de los partidos, entre otras (Pridham, 1986). No puede dejarse de lado el papel central que tienen sus protagonistas en los acuerdos para formar coaliciones y los incentivos para hacerlo, entre éstos destacan poder compartir la contabilidad electoral de la que gozan, contabilidad que las hace más competitivas en caso de que los ciudadanos voten por ellas.

Como ejemplo del efecto de la formación de las coaliciones en la dinámica interna de los partidos, al momento de escribir estas líneas, encontramos que es un elemento central en la pugna de las facciones

1 En el caso del PRI los candidatos a jefe de Gobierno y a alcaldes no formaron coalición partidaria en la capital, la cual solía establecerse con el Partido Verde Ecologista de México (PVEM).

2 Por ejemplo, la escritora Elena Poniatowska y la actriz Jesusa Rodríguez, destacadas integrantes del grupo cultural que apoya a Andrés Manuel López Obrador, protestaron el 14 de diciembre de 2017, cuando éste presentó dicha alianza. De igual manera la comunidad LGBTT+ se inconformó.

3 Durante los múltiples mítines que realizó, López Obrador reiteró el combate a la corrupción como tema central. Otros tópicos de su programa de gobierno, a los que nos referimos más adelante, fueron mencionados por los candidatos locales y federales.

4 Como ocurrió con la propuesta electoral de Alejandra Barrales, candidata del PRD a la jefatura de Gobierno de la Ciudad de México. 
en el seno del PAN (partido que, como se sabe, perdió la Presidencia de la República después de que en las elecciones de 2016 había ganado siete de las 12 gubernaturas disputadas). ${ }^{5}$ La derrota ha generado agrios comentarios entre quienes se disputan la dirigencia panista. Por ejemplo, sobre la coalición con el PRD, Manuel Gómez Morín sostuvo:

Cómo no íbamos a perder las elecciones del 1 de julio si caímos tan bajo. Una alianza contra natura, una alianza contra nuestra esencia, contra nuestros principios, por el simple hecho de querer ganar una elección con un muchacho estúpido [Ricardo Anaya]. Un muchacho estúpido que no entendió, no comprendió que había sido elegido para ser presidente del PAN... [itálicas nuestras]. ${ }^{6}$

\section{La coalición que se nulificó entre sí}

En el esfuerzo por crear coaliciones que puedan "cachar todo" se fueron "descafeinando" los estatutos del PRD y del PAN con la finalidad de elaborar un programa de trabajo conjunto con propuestas muy generales (sobre las que más adelante nos detendremos). Más allá de dichas propuestas, el primer efecto de la coalición fue la confrontación de los intereses políticos relacionados con el reparto de candidaturas entre ambos partidos, no sólo en la Ciudad de México, sino en todo el territorio nacional. La coalición profundizó los enfrentamientos dentro del PAN y del PRD a causa de la entrega recíproca, pero no necesariamente equitativa, de candidaturas al otrora partido contrincante. Las facciones políticas del PRD (encabezadas por Nueva Izquierda), erosionadas a consecuencia de las pugnas suscitadas en las elecciones internas de 2014 y las elecciones locales de 2015 (cuando perdieron cinco delegaciones a manos de Morena), se desgastaron aún más con la coalición; por otro lado, comenzó un creciente desacuerdo con las organizaciones territoriales todavía ligadas a este partido (por ejemplo, las de Iztacalco, Coyoacán e Iztapalapa).

El PRD, que era predominante en la Ciudad de México, terminó cediendo siete distritos federales a sus nuevos compañeros de coalición (el PRD sólo contendió en 13 distritos federales de los 24 que integran la Ciudad de México). No obstante, en cuanto a las alcaldías, este partido tuvo candidatos en 11 de ellas, mientras que el PAN únicamente en tres y MC en dos. En todo caso, con excepción de Benito Juárez (que ganó) y Miguel
Hidalgo (que perdió), las posibilidades del pan en la Ciudad de México eran limitadas.

El desenlace de la negociación arriba descrita no fue homogéneo. Algunas organizaciones con acuerdos o alianzas con liderazgos fuertes vinculados al poder legislativo local, con el control delegacional, o ligadas a grupos de interés económico y político dispuestos a emplear la violencia (como en Coyoacán), se mantuvieron relativamente unidas alrededor de dichos liderazgos asociados al PRD. Pero en delegaciones con mayor extensión territorial, donde la estructura política es más compleja debido a su tamaño y a la fuerza territorial de sus organizaciones, hubo reticencia a seguir apoyando al PRD, sobre todo cuando percibieron que la Presidencia de la República y la jefatura de Gobierno quedarían en manos de Morena.

El 8 de diciembre de 2017 se registró ante el Instituto Nacional Electoral (INE) la coalición electoral denominada Por México al Frente, antes llamada Frente Ciudadano por México, Frente Amplio Democrático y Frente Amplio Opositor. El candidato a la Presidencia era Ricardo Anaya Cortés, y para jefa de Gobierno de la Ciudad de México se postuló a Alejandra Barrales. En la plataforma de la coalición Por México al Frente es fácil encontrar los puntos que fueron soslayados y se convirtieron en ausencias y silencios. Se afirmaba que la propuesta resultaba de la aportación de los tres partidos que la integraban y de ciudadanos especialistas en distintos temas quienes habían contribuido con sus ideas, planteamientos y experiencia. ${ }^{7}$ Pero predominó una miscelánea de declaraciones y tomas de posición, muy afines con la forma en que el PAN gusta mostrarse; enarbolando principios generales de política pública condimentada con elementos morales y valores altruistas. El resultado evidencia que el PAN llevó la batuta en la redacción de la plataforma, lo cual no fue suficiente para influir en el desempeño electoral de la coalición en la Ciudad de México y en el país (con excepción de Guanajuato).

Las contradicciones entre las plataformas de ambos partidos se disolvían, como se ha dicho, en declaraciones generales producto de concesiones y matices que desdibujan los principios de ambos partidos, sobre todo del PRD. Tenemos dos ejemplos dejados de lado: la diversidad sexual y, nada menos, la identidad partidaria. Con relación a la primera, en los estatutos y declaración de principios del PRD puede leerse en el capítulo II, inciso g), que: "reconoce la pluralidad de la sociedad mexicana, por tanto, garantizará la

5 Cuatro de ellas en coalición con el PRD. Por lo demás, el PRD y el PAN ya habían competido coaligados en 24 ocasiones más.

6 Mayolo López, "Llaman a Anaya 'Muchacho Estúpido', en Reforma, Nacional, 19 de octubre de 2018 , p. 7.

7 "Libro de Propuestas", en la página web de Ricardo Anaya <https://www.ricardoanaya.com.mx/>, p. 12 [21 de mayo de 2018]. 
presencia de los sectores indígenas, migrantes, de la diversidad sexual u otros en sus órganos de dirección y representación, así como en las candidaturas a cargos de elección popular en los términos del presente Estatuto y sus reglamentos" (PRD, 2015a: 3 y 5). Este partido establece en su declaración de principios que:

Reconocemos nuestra diversidad étnica, sexual, cultural, religiosa y de cualquier tipo, y nos pronunciamos por el respeto a nuestras diferencias, teniendo como principios la dignidad, el valor de las personas, la igualdad de derechos de hombres y mujeres, así como, el rescate y conservación de nuestro medio ambiente. Nos declaramos promoventes del cambio, del progreso social y de elevar el nivel de vida de la sociedad dentro del concepto más amplio de libertad y justicia.

[...]

Ratificamos nuestro compromiso de garantizar el pleno ejercicio de todos los derechos de las poblaciones Lésbico, Gay, Transexual, Transgénero, Travesti, Bisexual e Intersexual (LGTTtBI) y otro tipo de orientación sexual, oponiéndonos a cualquier forma de discriminación en los ámbitos: laboral, civil, familiar, gubernamental o en cualquier otra esfera de la vida social y política [PRD, 2015b: 1 y 16$]$.

Por lo que se refiere a la identidad del PRD como partido y su relación con la sociedad, se afirma:

El PRD se solidariza con las luchas obreras, campesinas, populares, feministas, por respeto a la diversidad sexual, las ambientalistas, estudiantiles, las reivindicaciones indígenas y los movimientos por la protección de los derechos humanos. Se reconoce también en los anhelos de libertad y justicia social presentes en los movimientos de liberación nacional y la izquierda internacionalista [PRD, 2015b: 8].

Por supuesto estos principios y declaraciones quedaron, como se ha dicho, anulados en las propuestas con base en las cuales se integra la coalición, probablemente a causa del interés mayor de buscar una estrategia para obtener más votos, lo que permitió que predominaran los principios sobre discriminación, equidad de género y familia sustentados por el PAN. En cuanto a la discriminación el PAN manifiesta:

Toda forma de discriminación o desigualdad de oportunidades por razones de sexo, edad, capacidad física, etnia, religión, convicción, condición económica o cualquier otra, debe ser rechazada, corregida y en su caso sancionada [PAN, 2002: 3].
Por supuesto no está considerada la orientación sexual como uno de los temas relacionados con la discriminación, y la equidad de género está acotada, como puede leerse en la siguiente declaración:

La equidad de género significa que mujeres y hombres deben desarrollarse plena, libre y responsablemente. La discriminación existente contra la mujer en la familia, el trabajo, la política y en las demás esferas sociales es inaceptable. Los hombres y mujeres deben reconocer mutuamente su valor propio, y responsabilizarse el uno del otro, compartiendo las tareas que les corresponden dentro y fuera de la familia, sobre la base de igualdad de derechos y de obligaciones [PAN, 2002: 3].

Finalmente, en sus principios doctrinarios queda claro que será la familia la base de todo.

La familia es el cauce principal de la solidaridad entre generaciones. Es el espacio primario de la responsabilidad social, que debe ofrecer la más leal red de seguridad y de afecto ante contingencias y amenazas. Compete a la familia comunicar y desarrollar los valores morales e intelectuales necesarios para la formación y perfeccionamiento de la persona y de la sociedad [PAN, 2002: 5].

El acuerdo partidario resultó costoso en términos electorales para la coalición Por México al Frente porque anuló las potencialidades que cada partido poseía para atraer fracciones específicas del electorado de la capital del país y muy probablemente del conjunto del país donde se celebraron elecciones.

El PRD ahondó su derrota al haberse asociado con el PAN en un contexto político en donde ambas fuerzas habían sido reiteradamente contrapuestas. Por su parte, el PAN se contrajo a su espacio más usual: la demarcación Benito Juárez, perdiendo Miguel Hidalgo.

Si tomamos el grado educativo como indicador $\mathrm{y}$ revisamos las secciones electorales, encontramos que en las elecciones de 2015 los votantes del PRD estaban menos distribuidos entre los diferentes niveles educativos que aquellos que sufragaron por Morena (véase gráfica 1).

La regresión lineal muestra que el comportamiento de los votantes hacia el PRD en dichas elecciones decae de manera sostenida, poniendo en evidencia que las personas con menor grado de estudios sufragaron por ese partido. En contraste, quienes lo hicieron por Morena manifiestan otro comportamiento. La votación hacia ese partido decae ligeramente de 30 a $25 \%$ hasta los 11 años de escolaridad (preparatoria). A partir de ese momento, comienza a disminuir hasta un promedio de $18 \%$ de votos recibidos asociados a 14 años de 


\section{Gráfica 1. Porcentaje de votos vs. grado promedio de escolaridad en la sección electoral 2015}

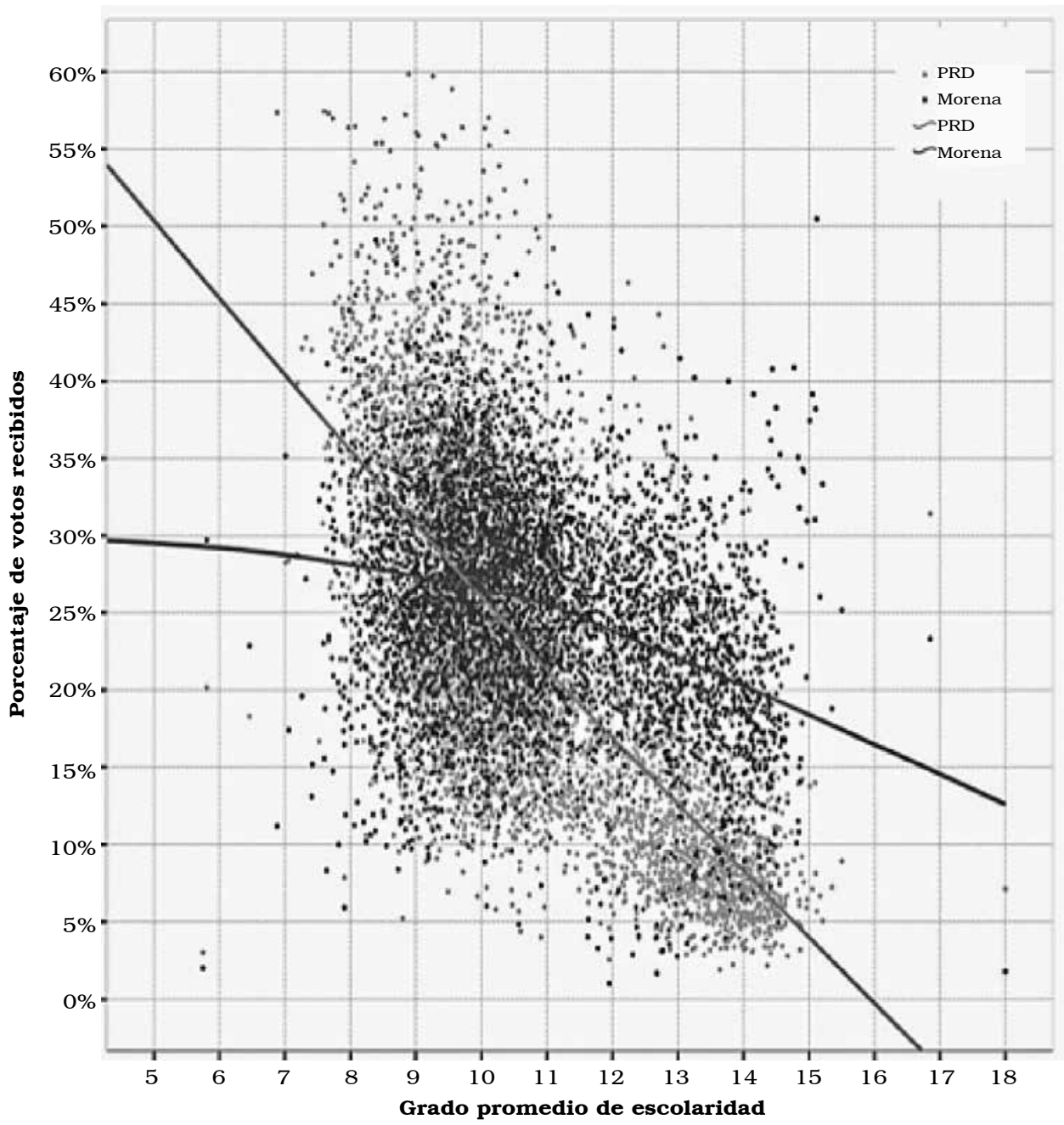

Fuente: Resultados electorales 2015. Instituto Electoral del Distrito Federal y Escolaridad por AGEBs. Instituto de Estadística, Geografía e Informática.

educación. Lo anterior indica que la votación hacia Morena está más dispersa entre la población.

Hasta 2015 (Tejera y Castañeda, 2017), el voto al PRD fue predominante en las secciones electorales con menor índice de desarrollo social (IDs). La etnografía realizada revela que estas secciones se asocian con la presencia de organizaciones territoriales con control político-electoral alimentadas con base en relaciones clientelares (Tejera y Rodríguez, 2015).

El voto para Morena en las elecciones del 2015 se concentra más en una franja específica de la población que comparte con el PRD los estratos de menor educación, pero abarca sectores que, tomando sólo como referencia este indicador, se extienden hacia un mayor nivel educativo. Lo anterior prefigura el comportamiento electoral de 2018 hacia Morena que, al menos en la capital del país, fue relativamente multisectorial.
Es probable que al detectar esta situación el PRD haya buscado disolverse, por decirlo así, en el PAN para competir por votantes de mayor nivel educativo.

Las elecciones de 2015 marcan el inicio de la retirada del PRD de la Ciudad de México como partido preponderante, y esto debido a una combinación de su desprestigio con el ascenso de Andrés Manual López Obrador como expectativa.

Después de las elecciones de ese año se afirmó que la pérdida de tres delegaciones a manos del PRI y una más que retornó al PAN se debía a la división de la izquierda. Mas, aun cuando se hubiesen sumado los votos del PRD y Morena la izquierda hubiera perdido en Cuajimalpa (PRI), Milpa Alta (PRI) y Benito Juárez (PAN), y mantenido Magdalena Contreras (PRI). Es decir, incluso conservando los votos que se fueron a Morena, los resultados del PRD no se habrían modificado mucho. 


\section{Evangélicos contra mesiánicos: Juntos Haremos Historia}

La coalición formada por Morena, PT y PEs, presenta su propuesta el 13 de diciembre de 2017 designando a López Obrador como precandidato a la Presidencia. En el reparto de candidaturas se acuerda que Morena elegirá 150 distritos electorales federales y 32 distritos al Senado, el PT a 75 diputados y 16 senadores y el PES también a 75 diputados y 16 senadores. $^{8}$

No obstante que el presidente del PEs, Hugo Eric Flores Cervantes, afirmó que habían decidido ponerse "del lado correcto de la historia", ${ }^{9}$ la posición de este partido es claramente contraria a la izquierda en aspectos como el secularismo, el derecho de la mujer a decidir sobre su cuerpo y lo que critican como mesianismo, lo cual pareciera, tal vez, dedicado a López Obrador:

El mesianismo, esa ilusión nacional de que llegará un líder o un grupo de iluminados que podrán sacar del atraso a millones de mexicanos sólo con "voluntad política". El mesianismo es, ha sido y será, si perdura, una de las peores creencias culturales de nuestra sociedad [PES, s. f.: 14].

Empero, pragmatismo mata principios y los acuerdos de una comisión interpartidaria dan como resultado más de cien programas, entre los cuales prevalecen los expuestos en el Proyecto Alternativo de Nación 2018-2024 sobre materia económica, política, social y educativa, todos los programas se apegaban a los mandatos de: legalidad y lucha contra la corrupción, combate a la pobreza, recuperación de la paz, viabilidad financiera, equidad de géneroy, por último, desarrollo sostenible (Morena, s. f.: 5).

Los rubros esenciales de la propuesta de gobierno de la coalición evidencian la preeminencia de la propuesta de Morena sobre la del PT y el PEs. Se diluyen las contradicciones programáticas de Morena y el PEs, mientras que el PT se subsume a Morena. El interés electoral disuelve cualquier antagonismo en aras de contar mutuamente con los votos de uno y otro partido. ${ }^{10}$

Sin embargo, al revisar los estatutos del PES se descubren oposiciones importantes con Morena. El núcleo de su propuesta estriba en el "Encuentro de
Familias". Sus proyectos, programas y objetivos específicos pretenden "el estudio de la institución familiar y encontrar los mecanismos para su fortalecimiento como célula básica de nuestra sociedad" (PEs, s. f.: 2). El PEs sostiene que su acción política está encaminada a fortalecer la familia.

En Encuentro Social creemos que la institución familiar es origen y fin de nuestra riqueza como pueblo y de nuestro destino como nación [PEs, s. f.: 3].

Este partido se declara en "contra de las ideologías" (sic) de derecha e izquierda, pero:

Tomamos las mejores causas de ambas ideologías. De la derecha genuina tomamos las libertades económicas, empresariales, de propiedad, de respeto al Estado de derecho, de los valores éticos, morales, familiares. De la izquierda auténtica la preocupación y dedicación por los que menos tienen, la búsqueda de la igualdad, el respeto a los derechos humanos, la organización social comunitaria [PEs, s. f.: 6].
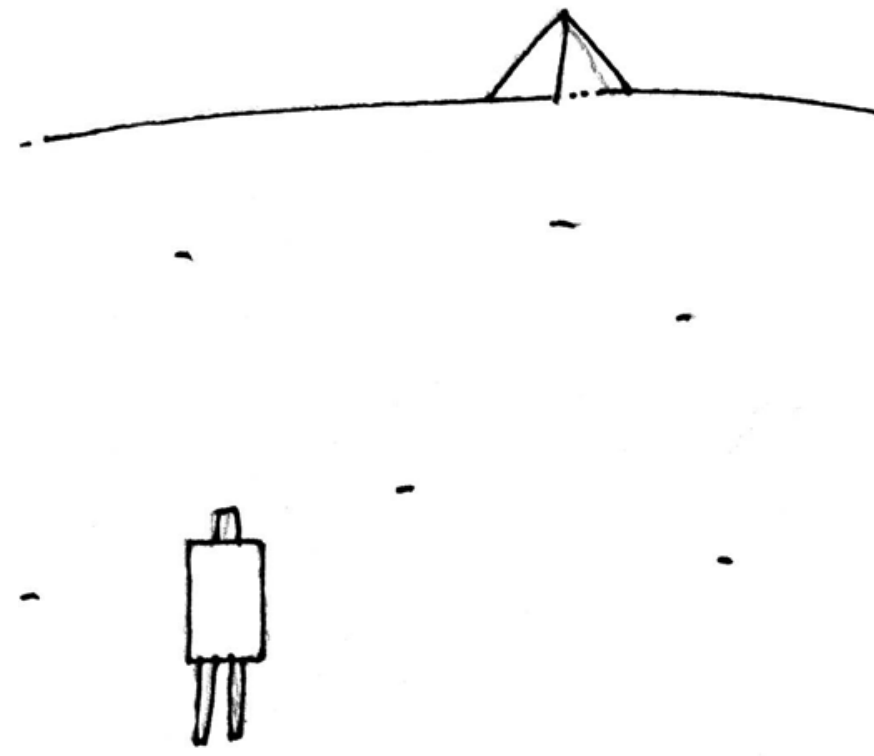

8 Como se sabe, después de la elección hubo cambios de un partido al otro, modificando el número de diputados de la bancada de esta coalición hasta estar muy cerca de obtener la mayoría calificada en el Congreso. Para lograrla tendrá que negociar con MC.

9 "La única opción para cambiar el país es la que encabeza AmLO: Hugo Eric Flores", en El Financiero Bloomberg, 13 de diciembre de 2017 <https: / / www.youtube.com/watch?v=XsTrelNcUQM> [14 de diciembre de 2017].

${ }^{10}$ Que esta intención no haya funcionado finalmente para el PEs, el cual, como es de todos conocido, perdió su registro como partido, no soslaya la existencia de un acuerdo pragmático para obtener votos. 
Encuentro Social dice tomar de la Declaración de los Derechos Humanos de la Carta de las Naciones Unidas un párrafo que resume sus principios, pero no advierte al lector que en realidad está reescribiendo el texto, el cual redacta del siguiente modo: "Cada persona adulta tiene el derecho de casarse con una persona del sexo opuesto, con libre consentimiento, y de formar una familia" (PEs, s. f.: 36). ${ }^{11}$

\section{Coaliciones, proselitismo electoral y habitantes de la Ciudad de México}

Como se dijo al inicio, uno de los temas a tratar aquí estriba en ahondar si las coaliciones modificaron las características y contenidos proselitistas de las campañas. Ya mostramos que Por México al Frente diluye al PRD en las propuestas panistas, mientras que, en el caso de Juntos Haremos Historia, es el pes el que desaparece en el planteamiento programático. ¿Sucedió lo mismo en el ámbito de las campañas electorales? ¿El proselitismo de la coalición también se diluyó en las propuestas, o se realizó una campaña con base

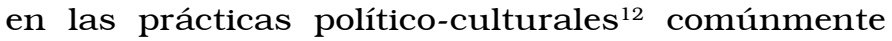
empleadas por cada uno de los partidos? Para abordar estos cuestionamientos se realizó un periodo de investigación etnográfica con el apoyo de un equipo de antropólogos dirigido por quien esto escribe, el cual se distribuyó en varias delegaciones siguiendo candidatos de ambas coaliciones.

\section{Cultura, ciudadanía y coaliciones: el carácter de los vínculos entre candidatos y electores}

El estudio puso en evidencia que las campañas electorales en las cuales los candidatos se relacionan frente a frente con los ciudadanos se ubican en un contexto donde, por un lado, se muestra la tendencia ciudadana a rechazar el proselitismo partidario y exteriorizar velada o abiertamente que todos los partidos (o sus candidatos) "son corruptos" o "son lo mismo", y, por otro, buscan o aceptan la cercanía de los candidatos, de manera señalada de aquellos del partido que está gobernando, o de aspirantes vinculados a los territorios en los cuales buscan el voto (Tejera, 2016). Esta particular forma de actuar es usual entre la población mayor de edad en zonas con bajo índice de desarrollo social, como algunas de Iztapalapa y Cuajimalpa, que se recorrieron acompañando candidatos durante sus actividades proselitistas. Por ejemplo, candidatas en Iztapalapa que llevan muchos años realizando trabajo de base en algunas colonias fueron reconocidas y recibidas con frases como: "a ti sí te vemos caminando con nosotros".

En los espacios territoriales donde los candidatos han estado vinculados con la población a través de la intermediación y relaciones clientelares más o menos sólidas, las preferencias electorales se modifican por el cambio de partido de los intermediarios o patrones y no a causa de convicciones políticas asociadas a programas o propuestas de los partidos que, por otro lado, son casi inexistentes en el ámbito del proselitismo electoral (con excepción de algunas de las propuestas de López Obrador que los candidatos de Morena recalcan). Lo anterior deviene en que a los ciudadanos no les importe el partido del candidato y votan por el que éste sugiera, siempre y cuando lo consideren uno de sus intermediarios.

En el caso de los jóvenes, fue común la tendencia a rechazar abiertamente a los candidatos, o ser más escépticos frente a ellos. Por esta razón, al margen de las prácticas proselitistas empleadas por los partidos (que abordaremos más adelante), éstas estuvieron matizadas por el carácter de las relaciones sociopolíticas en que fueron utilizadas.

La integración de las coaliciones se evidenció sustancialmente en la propaganda. Aquella con los logotipos del PAN y el PRD estuvo sujeta a comentarios ciudadanos irónicos o de rechazo, pues les resultaba extraña o absurda. En contraste, la propaganda de Morena les pareció menos paradójica por dos razones: los logotipos de los partidos eran menos evidentes $\mathrm{y}$, sobre todo, porque las propuestas de un partido como el pes eran desconocidas. En cualquier caso, el peso político de la figura de López Obrador (que estaba retratado en toda la propaganda de los demás candidatos) difuminaba la presencia de ese partido y las contradicciones de la coalición.

Lo cierto es que, con excepción de cuando se realizaron recorridos asociados de candidatos de partidos distintos, usualmente no se encaró a los ciudadanos con

${ }^{11}$ En realidad, en el artículo 16 de la Declaración Universal de los Derechos Humanos se lee: "1. Los hombres y las mujeres, a partir de la edad núbil, tienen derecho, sin restricción alguna por motivos de raza, nacionalidad o religión, a casarse y fundar una familia, y disfrutarán de iguales derechos en cuanto al matrimonio, durante el matrimonio y en caso de disolución del matrimonio. 2. Sólo mediante libre y pleno consentimiento de los futuros esposos podrá contraerse el matrimonio. 3. La familia es el elemento natural y fundamental de la sociedad y tiene derecho a la protección de la sociedad y del Estado". La cuestión, como se ve, es que no establece que tengan que ser hombre y mujer como lo pretendió el pes.

12 Acciones cuyos contenidos son aprendidos, reproducidos y modificados por la interacción entre cultura y política. Son prácticas que sintetizan imaginarios e intencionalidades políticas y tienden a mostrar cierta regularidad. 
el hecho de que el PRD y el PAN participaban de manera conjunta; y en cuanto al PEs no fue extraño que, en realidad, el candidato no fuera evangélico, sino un líder o representante de un grupo político local a quien se le "abrió espacio" en ese partido y en los recorridos no se comportaba como evangélico ni tampoco hacía énfasis en que se votara por ese partido, sino más bien por "la coalición de López Obrador". ${ }^{13}$

La mayoría de los candidatos que hicieron campaña en la Ciudad de México contendiendo en el marco de la coalición Juntos Haremos Historia, encabezada por Morena, cimentaron su campaña en la imagen de López Obrador. En las reuniones que celebraron con vecinos, aun cuando tuvieran muchos años haciendo trabajo político en una delegación (ahora alcaldía), emplearon parte del espacio para referirse a las propuestas de éste. Todo indica que muchos de ellos tenían la convicción, o habían sido instruidos como parte de la estrategia global de campaña, de que era muy importante destacar la presencia de López Obrador para, a su vez, obtener votos, como resultado de la tendencia de los ciudadanos a votar en cascada. Además la propaganda era muy similar: una imagen del candidato acompañado de López Obrador, para apoyar la sinergia proselitista entre las campañas locales y federales, a la vez que fortalecer la campaña presidencial.

La asamblea fue bastante improvisada y con una asistencia de entre 25 y 30 vecinos quienes escuchan las propuestas de la candidata a diputada federal por Morena quien se presentay, además, introduce a su candidata suplente y la candidata plurinominal federal por la $44^{a}$ circunscripción. La candidata habla por aproximadamente veinte minutos durante los cuales aborda algunas de las propuestas de López Obrador; por ejemplo, suprimir la reforma educativa, insistiendo en que, en realidad, fue una reforma laboral. En términos locales se refiere a la forma de canalizar agua de lluvia y volverla potable para la población. ${ }^{14}$

Los aspirantes con una larga trayectoria en la izquierda hicieron alusiones al candidato presidencial, mientras que quienes provenían de otros partidos como, por ejemplo, el aspirante de Morena a la alcaldía en Benito Juárez, quien ya había sido delegado por el PAN, fueron poco proclives a mencionar a López
Obrador y sus propuestas, concentrándose en las que ellos elaboraron para su campaña.

En cuanto a la coalición Por México al Frente en la Ciudad de México, los candidatos panistas aprovechaban la apertura de los territorios perredistas que les abría la coalición, lo que propició escenas inéditas en la capital del país; por ejemplo, que Ricardo Anaya levantara el brazo del perredista Julio César Moreno, quien buscaba gobernar Venustiano Carranza por segunda ocasión, frente a los comerciantes de los mercados de Jamaica y Sonora, ambulantes de la Merced, y habitantes de las unidades habitacionales a quienes les ofrecían apoyos "desde ya". ${ }^{15}$

Si bien el PAN aprovechó la apertura de los mítines organizados en zonas perredistas para acceder a un sector del electorado al que le sería difícil llegar, asimismo es cierto que, en muchos actos de campaña, si no estaba presente Anaya, los perredistas evitaban poner de relieve la presencia de candidatos panistas. Por ejemplo, Santiago Taboada y Margarita Martínez Fisher, candidatos a las alcaldías de Benito Juárez y Miguel Hidalgo, no eran anunciados en los mítines organizados por el PRD. No cabe duda de que, de cualquier forma, fue gracias a la presencia de los líderes perredistas que organizaban y llevaban asistentes a los actos de campaña del candidato presidencial panista, que éste pudo entrar a delegaciones o espacios identificados como "populares" y perredistas. De este modo, en un acto masivo perredista, Anaya pudo hablar diez minutos después del discurso de Moreno y Barrales. Los asistentes, como es usual, pasaron lista al término del mitin.

No obstante los esfuerzos de la coalición Por México al Frente por obtener votos buscando la convivencia de panistas y perredistas, lo que en realidad se logró hacer fue poner de manifiesto las contradicciones entre ambos partidos y los grupos sociales asociados a ellos. Pero quizá el momento más significativo no haya sido el cierre de campaña de Barrales, sino el del propio Anaya en León, Guanajuato, cuando:

Izquierdistas y derechistas, proabortistas y conservadores se unieron [...] en apoyo a Ricardo Anaya en el cierre de su campaña. En medio de banderas panistas surgió la que identifica a la comunidad lesbicogay, que ondeó a la par de las blanquiazules o amarillas. ${ }^{16}$

\footnotetext{
${ }^{13}$ Así, por ejemplo, durante el estudio etnográfico encontramos un candidato del Pes en Iztapalapa que, en realidad, es hijo de una de las dirigentes de comerciantes más influyentes de esa demarcación. Este candidato fue elegido diputado. Además, recuérdese como indicador de la poca capacidad del pes para competir, que casi la mitad de sus candidatos ganadores fueron integrantes de Morena (que regresaron a su partido al conformarse la Cámara de Diputados).

14 Santa Cruz Meyehualco, Iztapalapa (5 de mayo de 2018).

${ }^{15}$ Reforma, 2 de mayo de 2018, p. 3.

${ }^{16}$ Reforma, 28 de junio de 2018, p. 9.
} 


\section{Redes y territorios geográficos y simbólicos}

En materia de los procesos electorales en general, identificamos que en las campañas del PRD destacaba la defensa de territorios como patrimonio electoral como estrategia para ganar votantes. Este fenómeno ya se había visto con el PRI en 1997, cuando perdió el Distrito Federal en las elecciones para jefe de Gobierno (Tejera, 2003). Es decir, se observó un PRD en retirada $\mathrm{y}$, ante ello, la tendencia a delimitar territorios y a veces luchar por ellos con amenaza de violencia o, como en Coyoacán, con violencia abierta. Esta situación fue habitual al inicio de campaña, en especial por parte del PRD en contra de los candidatos de Morena.

La "defensa de los territorios" fue un fenómeno más amplio vinculado a las redes y organizaciones sociales con influencia territorial, las cuales han tenido tradicionalmente el papel de cohesionar el voto en torno a un partido. Dichas organizaciones no sólo son grupos urbanos con demandas particulares, sino articuladoras de intereses mediante los acuerdos que establecen con grupos o facciones partidarias. De igual modo fueron protagonistas de las disputas territoriales cubiertas por el manto de la lucha electoral de 2018, y los principales actores colectivos de los cambios de preferencias partidarias y apoyos hacia un candidato $\mathrm{u}$ otro. Las noticias de actos violentos por parte de grupos asociados a líderes territoriales en delegaciones como Coyoacán e Iztapalapa fueron atemperándose (al menos en Iztapalapa) mediante denuncias legales y difusión en los medios de comunicación masiva, pero no dejaron de estar presentes. Lo anterior propició diversas estrategias defensivas, sobre todo entre los candidatos de Morena. Una de las estrategias fue llegar a acuerdos con bandas locales para que éstas, a su vez, impidieran que fueran agredidos por aquellas que fueron cooptadas por líderes territoriales vinculados con el PRD. De esta forma se conformaron grupos de "autodefensa" (no se denominaron así), por un lado, y de "intimidación”, por otro, donde muchos de sus miembros tenían un amplio historial de violencia.

Algunos integrantes de los grupos asociados a Morena que fueron entrevistados hablaron de su actual incorporación a actividades de apoyo social y cultural en sus barrios, pero de igual modo se refirieron a una historia personal de consumo (y probablemente venta) de drogas y delincuencia urbana. Estos grupos acompañaban a los candidatos a las actividades pro- selitistas colaborando en la instalación de templetes, transporte de propaganda y entrega de regalos "utilitarios".

Durante el recorrido un grupo de jóvenes acompañan a la candidata unos pasos detrás. Uno de los integrantes sostiene que debido a las intimidaciones recientes estos jóvenes vienen custodiando a la brigada por si "se presenta algún inconveniente". ${ }^{17}$

También ocurrió que personas de los grupos en antagonismo se conocían entre sí y por eso comenzaron a utilizar capuchas, ya que después de los primeros conatos de enfrentamiento recibieron mensajes de que los irían a buscar a su casa o calle para golpearlos si seguían participando en dichas acciones. Los candidatos recurrieron también al INE, al Instituto Electoral de la Ciudad de México (IECM) y a la Fiscalía Especializada para la Atención de Delitos Electorales (FEPADE). La intimidación fue publicitada en los medios de comunicación y convertida en un elemento de propaganda para mostrar al PRD como violento. No obstante, la acción más efectiva fue desalentar la acción de los grupos intimidatorios mediante la contratación de bandas.

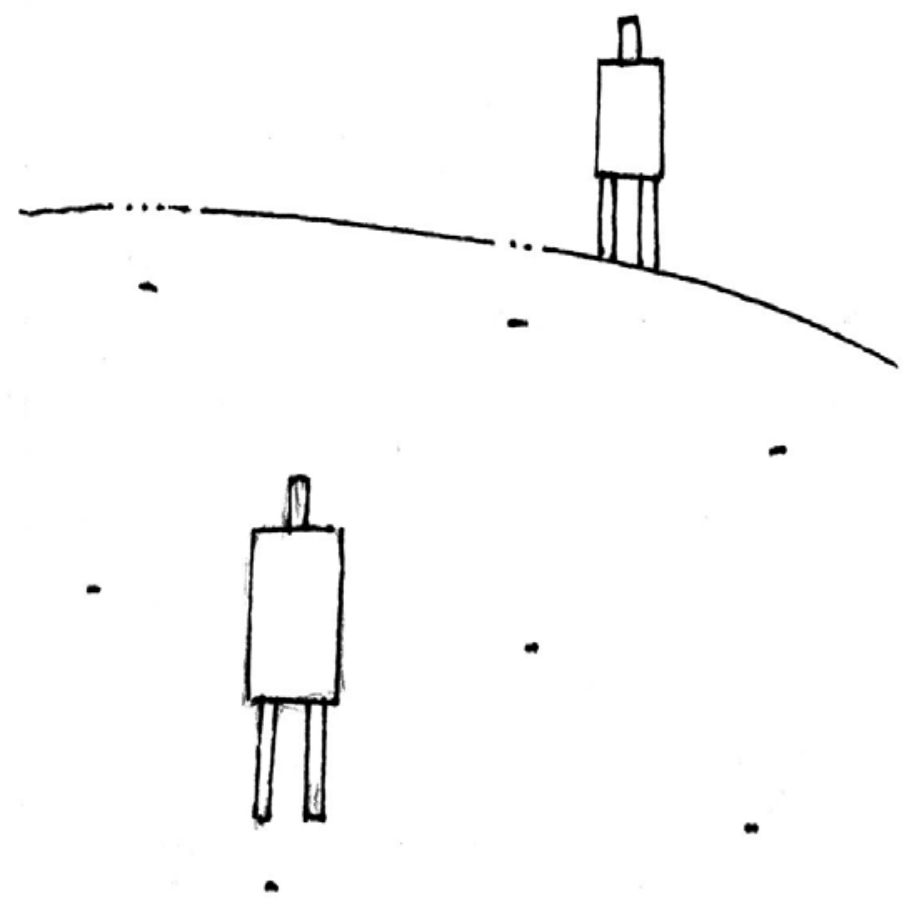

${ }^{17}$ Entrevista durante recorrido por Barrio San Miguel y la Purísima, Iztapalapa (5 de mayo de 2018). 
Los gobiernos delegacionales perredistas también desempeñaron un papel activo obstaculizando las actividades de los candidatos de Morena en la Ciudad de México. Como ejemplo podemos citar:

- Inicio de obras de mantenimiento por parte del gobierno perredista en la calle donde López Obrador tenía un mitin. ${ }^{18}$

- Negar la Plaza de la Constitución (Zócalo) a López Obrador para su cierre de campaña con el argumento de que una empresa ya la había apartado para transmitir en pantallas gigantes el Mundial de Futbol. ${ }^{19}$

- En Gustavo A. Madero, la delegación montó carpas y realizó eventos políticos y musicales en las colonias Juan González Romero, Constitución de la República, Unidad Habitacional San Juan de Aragón y el Pueblo San Juan de Aragón. En todos los casos Claudia Sheinbaum, en ese entonces candidata de Morena a la jefatura de Gobierno, tenía programados mítines políticos. ${ }^{20}$

- La candidata del PRD a la alcaldía de Gustavo A. Madero realizó una concentración en el lugar donde Sheinbaum planeaba llevar a cabo un mitin. En los otros dos puntos donde la candidata de Morena había programado reunirse con los vecinos, la delegación montó juegos de feria. ${ }^{21}$

Otra manifestación de disputa territorial es la simbólica, expresada en la colocación de mantas o propaganda política en domicilios particulares, como forma de identificar la preferencia política de los habitantes de una casa y de acotar una zona específica. En consecuencia, como parte de las tácticas para la delimitación político-territorial de zonas perredistas se realizan actos de vandalismo dirigidos a retirar, cortar y destruir la propaganda de domicilios particulares. Así ocurrió en Benito Juárez, donde vecinos denunciaron que la delegación utilizaba a sus trabajadores para retirar propaganda de candidatos opositores al Frente:

En la madrugada dos jóvenes (dejan) folletos de la delegación Benito Juárez en los que piden reportar daños por el sismo, para que se vayan a reparar. Pero, en realidad, van checando las paredes de las casas. Sin percatarse de que cámaras de videovigilancia los monitorean, los jóvenes arrancan una manta de la candidata de Morena a diputada local del muro de un edificio. "No sólo la retiraron. Con una navaja, con un cúter, trozan la lona en pedazos aquí mismo. Ellos tomaron video de lo que hicieron", mencionó una vecina. ${ }^{22}$

Las modificaciones en las preferencias electorales y el sufragio por un candidato determinado es un fenómeno más sutil que aquel al que son sujetos los ciudadanos cuando los partidos políticos se disputan las fachadas de las casas para instalar mantas (plotters) de apoyo a uno $u$ otro partido. Dicha disputa permite a los ciudadanos negociar con cada partido el monto entregado por colgar la propaganda. De esta forma, una manta, más que revelar una preferencia, podría ser indicador de una negociación monetaria.

Unos brigadistas comentan que en algunas zonas cercanas quitaron un par de lonas de Morena para poner la propaganda del PRD, y que las vecinas confiesan que les están pagando 200 pesos por colocarlas, pero que la gente afirma que sólo lo hacen por dinero. ${ }^{23}$

No en todos los casos es posible sustentar que los ciudadanos hicieran alguna transacción por poner las mantas, o por lo menos no sostuvieron abiertamente que estuvieran aceptando dinero, pero afirmaron que votarían por Morena, no obstante que en el frente de su casa tuvieran una manta del PRD.

El sentido de la competencia electoral y el contenido simbólico que los brigadistas adscriben a la colocación de una manta en una ventana o fachada de una vivienda no son iguales a los de muchos otros ciudadanos. Para unos implica membresía política; para otros, un negocio en el contexto de las campañas electorales. Lo anterior debe destacarse, porque en el trabajo de campo se identificó una tendencia de los militantes o empleados de los partidos (muchos brigadistas trabajan por un salario, no por convicción política) a simplificar las motivaciones ciudadanas ante las prácticas políticas de los partidos en el entorno de las contiendas electorales.

${ }_{18}$ Reforma, 2 de mayo de 2018, p. 3.

${ }^{19}$ Reforma, 7 de junio de 2018, p. 6.

${ }^{20}$ Reforma, 8 de junio de 2018, p. 5.

${ }^{21}$ Al respecto, Sheinbaum comentó: "Ahora ésa es su estrategia: Claudia y Chigüil [candidato a alcalde] van a hacer un evento, [pues] les ponemos una feria; van a hacer un evento allá, [pues] vamos a regalar despensas”. Reforma, 13 de junio de 2018, p. 4.

${ }^{22}$ Reforma, 6 de junio de 2018, p. 6.

${ }^{23}$ Recorrido por la colonia La Era, Iztapalapa (8 de mayo de 2018). 


\section{Las coaliciones como oportunidad $y$ pretexto}

La mayoría de las organizaciones territoriales de la Ciudad de México que buscaron acomodarse en Morena al ser patente que López Obrador tenía oportunidad de ganar la elección presidencial adujeron como causa para asociarse a Morena lo que denominaron "la pérdida de identidad del PRD”. Discurso compartido por los propios integrantes de ese partido: "la mudanza de líderes de base a Morena se debe a la pérdida de ideales del Sol Azteca”. ${ }^{24}$

La relación entre candidatos y organizaciones político-territoriales es compleja. Durante el estudio etnográfico se constataron "acuerdos” entre líderes de algunos de esos movimientos y los principales candidatos de los partidos, especialmente aquellos que aspiraban a convertirse en alcaldes. Por ejemplo, en materia de organizaciones con influencia territorial, Morena recibió a Gilberto Ensástiga, líder de la Unión de Colonias Populares (UCP) fundada hace 39 años $\mathrm{y}$ que integra agrupaciones sociales y sindicatos. ${ }^{25}$ Es fundador del PRD y exdelegado de Tláhuac. También fue diputado local y federal. Este líder argumentó:

Al tener la extraordinaria oportunidad político-electoral del 2018 para derrotar al régimen neoliberal, acudimos plenos y satisfechos [sic] de apoyar la candidatura a la Presidencia de la República de Andrés Manuel López Obrador y la de Claudia Sheinbaum a la Jefatura de Gobierno. Sheinbaum señaló que el PRD ya no representa a un modelo de transformación, por lo que aplauden el apoyo de la UCP y las alianzas a favor de su proyecto y aseguró que Ensástiga ocuparía un lugar en su campaña. ${ }^{26}$

La pugna política por territorios también se relaciona con las alianzas que puedan sumar votos o simpatizantes para determinado partido político o candidato, al negociarse necesidades de los integrantes de diversas organizaciones con los intereses políticos de sus dirigentes durante el periodo de campaña.

La candidata del PRD [Iztacalco] Elizabeth Mateos encabezó un acto en el que se anunció ayer que 200 personas de Morena abandonaron ese partido para sumarse a las filas del Sol Azteca. Por la tarde, Elizabeth Basáñez, diputada que suplió en la Asamblea Legislativa a Mateos, respaldó al candidato de Morena en esta demarcación, Armando Quintero. El exdelegado presentó a Basáñez en un evento, junto con el Movimiento Nacional por la Esperanza y la Federación de Organización para el Desarrollo Social (Fodesac), ambos gremios populares de Iztacalco, que apoyaban al PRD y que Basáñez representa. "Son más o menos unos 5 mil militantes de toda la organización", aseguró el exdelegado. ${ }^{27}$

Ciertas organizaciones territoriales con influencia transdelegacional calcularon en el transcurso de las campañas electorales que las posibilidades de que el PRD perdiera las elecciones locales eran altas y rompieron con este partido aduciendo su alianza con el PAN.

En un mitin de López Obrador en Iztapalapa hace acto de presencia un grupo del Frente Popular Francisco Villa México Siglo xxi, que en los últimos años ha apoyado al PRD. Uno de sus integrantes sostiene "Sí, estábamos apoyando al PRD, pero acabamos de romper debido a que nuestros ideales como Frente Popular no empatan con la coalición en que el PRD participa y ha perdido su identidad. Por lo tanto, ahora estamos apoyando a los candidatos de Morena en Iztapalapa y sobre todo a López Obrador”. ${ }^{28}$

También dirigentes sociales de colonia o manzana buscan posicionarse políticamente en el proceso de campaña, ofreciendo su apoyo y, sobre todo, sus redes a los candidatos, para que realicen proselitismo electoral en sus colonias o manzanas, mediante la organización de reuniones y otras actividades.

Antes de iniciar el recorrido, un señor de edad mediana se acerca a la candidata y le pide unirse a su campaña. Se sabe que es un líder social de colonia, aunque en ese momento no tiene algún cargo. Durante el recorrido demuestra que conoce a la mayoría de los habitantes de la zona y que los vecinos lo siguen y respetan. La candidata le permite que guíe la caminata y llame a los vecinos, quienes confían en él, lo que permite que la candidata tenga mayor aceptación y se le facilite la relación con los habitantes de la colonia. ${ }^{29}$

\footnotetext{
${ }^{24}$ Reforma, 2 de mayo de 2018, p. 4.

${ }^{25}$ Reforma, 17 de abril de 2018, p. 4.

${ }^{26}$ Reforma, 17 de abril de 2018, p. 4.

${ }^{27}$ Reforma, 30 de mayo de 2018 , p. 3.

${ }^{28}$ Mitin de López Obrador, Deportivo de Santa Cruz Meyehualco, Iztapalapa (7 de mayo de 2018).

${ }^{29}$ Recorrido proselitista, colonia Vicente Guerrero, Iztapalapa (4 de mayo de 2018).
} 


\section{Conclusiones}

Para concluir, puede sostenerse que tanto Por México al Frente como Juntos Haremos Historia pasaron por un periodo de negociaciones en el cual se generaron tensiones intrapartidarias derivadas no solamente de las divergencias programáticas, sino sobre todo del desplazamiento de militantes de las candidaturas, lo cual fue el elemento de desgaste más importante. En algunas zonas de la Ciudad de México hubo huelga de brazos caídos por esta circunstancia; en otras, de manera abierta o soterrada, los perredistas hicieron campaña para Morena; en muchos casos, los dirigentes de diversas organizaciones urbanas se cambiaron de un partido a otro.

Ahora bien, en cuanto a si las coaliciones modificaron las actividades proselitistas de los partidos que las integraron, podemos aseverar que hubo pocos cambios significativos en las prácticas cotidianas de los candidatos de los diferentes partidos. Más allá de las declaraciones de los dirigentes partidarios en cuanto a que la coalición fortalecía las posibilidades de incrementar la votación para los partidos que la integraban (con certeza una razón para integrarlas), en las campañas cara a cara, los candidatos poco hicieron por convencer a los votantes potenciales de que sufragaran por las coaliciones. Durante el estudio etnográfico pudo constatarse que dichos candidatos buscaron atraer los votos hacia su partido y candidatura, haciendo a un lado las coaliciones, por temor a que los ciudadanos se confundieran y votaran por otros partidos. Bajo estas condiciones, y como puede comprobarse en los resultados electorales finales, las coaliciones poco contribuyeron en los votos obtenidos por cada partido. Ante lo confuso que para muchos ciudadanos implicaba esto, dirigieron su voto al partido o candidato de su elección, sin considerar ventajas o desventajas de ello en términos de coalición, lo cual se alimentó de las voces que pidieron que no se votara por las coaliciones para evitar que los partidos satélite obtuvieran votos y presupuesto. El electorado rechazó la presencia de otros partidos que no fueran los principales con el razonamiento de que ya es "mucho gasto" y hay "mucho partido", como mencionaron coloquialmente los ciudadanos durante el trabajo de campo. Así, Encuentro Social perdió el registro aunque, paradójicamente, tiene bancada en la Cámara de Diputados. En síntesis, el comportamiento electoral ciudadano se dirigió a sufragar por los partidos asociados a sus candidatos y la votación hacia las coaliciones fue marginal.

Las prácticas y temáticas proselitistas empleadas por ambas coaliciones no fueron sustancialmente distintas de las observadas en elecciones anteriores y, en todo caso, estuvieron marcadas por las ofertas de los candidatos, o por las prácticas de intercambio de votos por bienes, servicios y atención delegacional. Pero, como ya se ha destacado, dichas ofertas y prácticas fueron combinadas con estrategias utilizadas usualmente por grupos políticos que han mantenido control territorial, que se habían observado en otras elecciones y que se emplearon como respuesta ante el peligro real de perder la elección. Ése fue el caso de lo observado en Coyoacán e Iztapalapa.

Las contradicciones políticas de las coaliciones desde la perspectiva ciudadana se hicieron evidentes en la propaganda electoral, en especial en la del PAN que, como ya se mencionó, permitía la fácil identificación de los logotipos del PAN y el PRD en carteles, mantas y espectaculares, así como en los mítines de cierres de campaña de Alejandra Barrales y de Ricardo Anaya, pese a que dichos partidos habían sido contrincantes durante los últimos 20 años en la Ciudad de México; por lo tanto, puede suponerse que la evaluación de sus dirigentes sobre el efecto que tendría en los votantes fue relegado ante el cálculo de las ventajas electorales. De esta forma pasaron equivocadamente por encima de las convicciones y percepciones políticas de muchos habitantes de la ciudad. Esta estrategia no sólo no evitó la derrota del PRD, sino que lo desgastó aún más; en cambio, el "voto duro" del PAN permaneció hasta cierto punto fiel, y conservó la "laguna azul”: la demarcación Benito Juárez.

Las coaliciones parecen haber generado entre los partidos expectativas muy alejadas del comportamiento de los votantes, quienes rechazaron con su voto estas asociaciones, en particular cuando ellas coaligaron a partidos con signos políticos opuestos.

Como puede verse en el mapa 1, que organiza las secciones electorales en cinco clusters en términos del comportamiento electoral, los panistas se mantuvieron firmes en las secciones electorales que usualmente han sido de ese partido, repartidas en Miguel Hidalgo (Bosques de las Lomas), Cuajimalpa (Santa Fe), la mayor parte de Benito Juárez, una zona de Álvaro Obregón, otra de Coyoacán y una porción de Tlalpan.

El caso de Morena y el Pes fue distinto, no porque sus plataformas políticas no sean contrapuestas, como se ha mostrado a grandes rasgos, sino porque este último es desconocido por la mayoría de los capitalinos. Cabe precisar que el PEs no ganó una sola sección electoral en la Ciudad de México. Un partido pequeño y con poca trayectoria política no afectó la campaña de López Obrador más que en los sectores con mayor información política. Incluso, en el cierre de campaña del candidato de Morena, su presencia 


\section{Mapa 1. CDMX: Votación para las alcaldías por sección}

$$
2018
$$

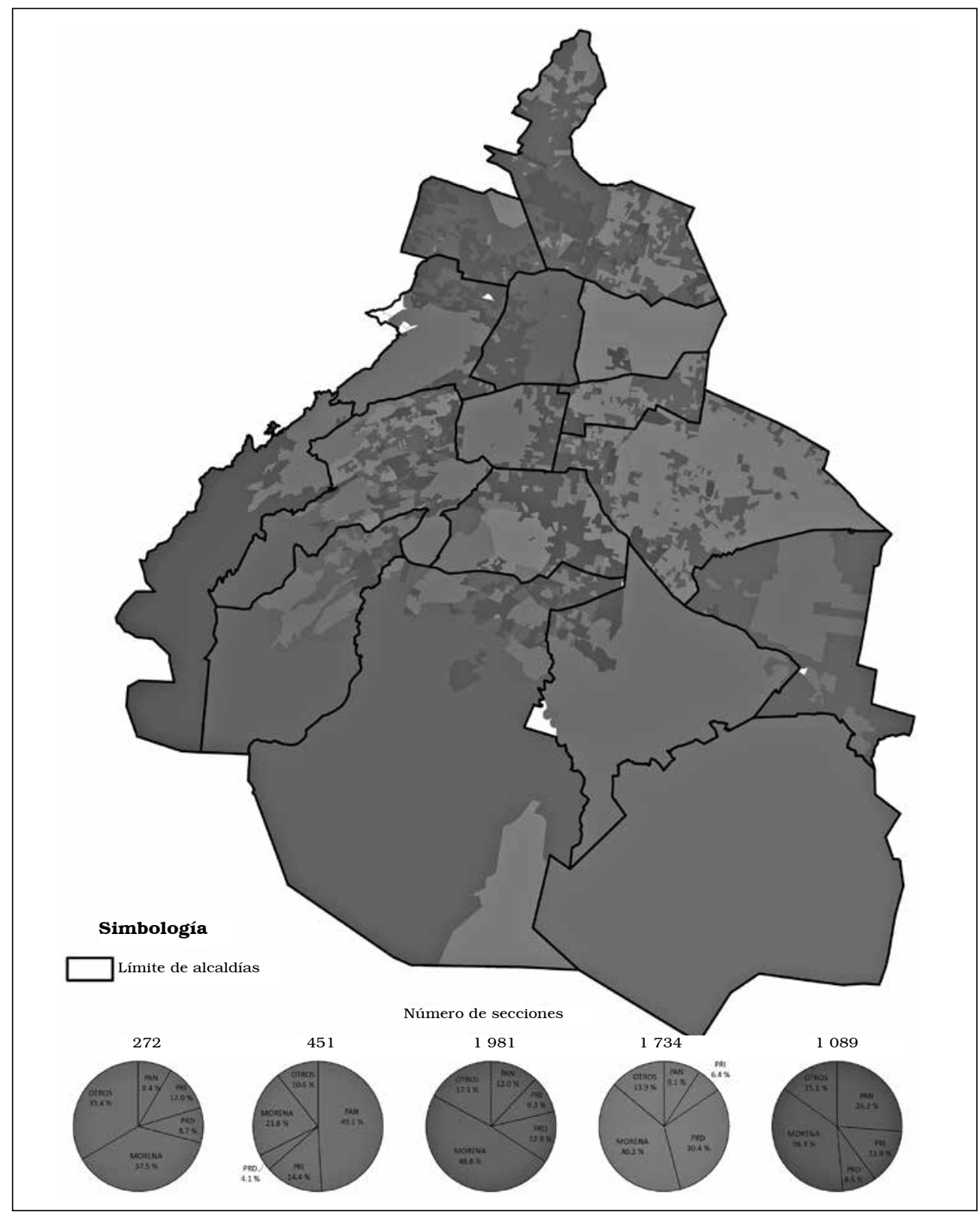

Fuente: Resultados electorales 2018. Instituto Electoral de la Ciudad de México.

hubiera sido ignorada por completo si no fuera porque un integrante de ese partido proyectó en las paredes del Estadio Azteca un láser con el nombre de ese partido. Con esta excepción, la presencia del PEs fue totalmente diluida por Morena.

En el transcurso del artículo varios de los procesos políticos descritos están cruzados por la influencia de las redes territoriales de carácter político-clientelar-en particular en zonas con bajo índice de desarrollo social-, las que influyeron en los resultados electorales. Pero, en otros, fue evidente que la vinculación electoral entre el PAN y el PRD en la propuesta para jefatura de
Gobierno generó rechazo entre los votantes. El mapa 1 revela que las preferencias electorales tradicionales se mantuvieron y en las secciones electorales panistas este partido conservó la mayoría de votos para candidatos a alcaldes. Por su parte, quienes habían votado por el PRD lo hicieron mayoritariamente por Morena, salvo en la alcaldía de Coyoacán. Un grupo político ha convertido a esa demarcación en su botín, malversando recursos públicos dirigidos a la reconstrucción de los inmuebles dañados por el sismo de 2017 e incitando la corrupción ha logrado mantener el favor de un sector del electorado. 


\section{Fuentes}

Katz, Richard y Peter Mair

2009 "The Cartel Party Thesis: A Restatement", en Perspectives in Politics, vol. 7, núm. 4, diciembre, pp. 753-766.

Kitschelt, Herbert

2018 "Cartels and Competition", en Henrick Enroth y Magnus Hagevi (eds.), Cartelization, Convergence or Increasing Similarities, ECPR Press [libro electrónico].

Lipset, Seymour (ED.)

2017 Party Coalitions in the 1980s, Routledge, Nueva York.

Morena

s. f. "Plataforma electoral y Programa de Gobierno" <https: / / elecciones.sociales.unam.mx/wpcontent/uploads / 2018/02/MORENA.pdf>.

PAN

2002 "Proyección de Principios de Doctrina del Partido Acción Nacional" <https://www. pan.org.mx/wp-content/uploads / 2013/04/ Principios-de-doctrina-2002.pdf>.

PES

s. f. "Declaración de Principios Encuentro Social" <http: / / pesdf.com /wp-content/uploads /

PRD

2015a "Estatuto del Partido de la Revolución Democrática" <http: / /www.prd.org.mx/documentos / basicos /ESTATUTO.pdf>.

PRD

2015b "Declaración de principios"<http: / / www.prd. org.mx/documentos / basicos/DECLARACION PRINCIPIOS.pdf $>$.
Pridham, Geoffrey

1986 Coalitional Behaviour in Theory and Practice: An Inductive Modelfor Western Europe, Cambridge University Press, Cambridge.

RUPARELIA, SANJAY

2015 Divided We Govern: Coalition Politics in Modern

STEFURIUC, IRINA India, Oxford University Press, Oxford.

2015 Government formation in Multi-Level Settings, TEJERA, Héctor Palgrave Macmillan [libro electrónico].

2003 "No se olvide de nosotros cuando esté allá arriba”. Cultura, ciudadanos y campañas políticas en la Ciudad de México, Miguel Ángel Porrúa, México.

TEJERA, Héctor

2016 "La gente no sabe por quién vota; tiene que hacerlo así, porque así se hace". Estructura política, identificaciones clientelares y procesos electorales en la Ciudad de México, Universidad Autónoma Metropolitana/Gedisa,

TEJERA, HÉCTOR México.

y Diana Castañeda

2017 "Estructura política, redes político-clientelares y oscilaciones electorales en la Ciudad de México", en Perfiles Latinoamericanos, vol. 25, núm. 50, julio-diciembre, pp. 129153.

Tejera, Héctor

Y EMANUEl RoDRÍGUEZ

2015 "Las paradojas de la democracia: partido dominante, gobiernoy redes políticas en la Ciudad de México", en Estudios Sociológicos, vol. XXXIII, núm. 98, mayo-agosto, pp. 375-408. 